\title{
Purification of Sulphate Leach Liquor of Spent Raneynickel Catalyst Containing Al and Ni by Solvent Extraction with Organophosphorus-Based Extractants
}

\author{
Satunuri Venkateswar Rao, Dong Hyo Yang, Jeong Soo Sohn, and Soo-Kyung Kim \\ Urban Mining Research Team, Korea Institute of Geosciences and Minerals Resources (KIGAM), 92 Gwahang-no, Yuseong-gu, \\ Daejeon 305-350, Republic of Korea \\ Correspondence should be addressed to Soo-Kyung Kim, skkim@kigma.re.kr
}

Received 14 October 2011; Accepted 11 December 2011

Academic Editor: Cesar Mateo

Copyright (c) 2012 Satunuri Venkateswar Rao et al. This is an open access article distributed under the Creative Commons Attribution License, which permits unrestricted use, distribution, and reproduction in any medium, provided the original work is properly cited.

\begin{abstract}
Solvent extraction (SX) separation of $\mathrm{Al}$ from Ni sulphate leach liquor (LL) of spent Raneynickel catalyst containing $0.12 \mathrm{M} \mathrm{Al}$ and $1.448 \mathrm{M}$ Ni using organophosphorus extractants has been investigated. Optimization of process conditions includes aqueous $\mathrm{pH}$, extractant concentration, phase ratio, and stripping. Comparison of $\mathrm{Al}$ extraction efficiency with $0.45 \mathrm{M}$ extractant concentration for TOPS 99, PC 88 A, and Cyanex 272 at an equilibrium pH of 2.23 was $81.8 \%, 98.6 \%$, and 75\%, respectively. The corresponding coextraction of $\mathrm{Ni}$ was $0.65,0.6$, and 0.9 . Among the three extractants screened, PC 88A showed better extraction efficiency for $\mathrm{Al}$ at lower $\mathrm{pH}$ values than the others. Using $0.45 \mathrm{M} \mathrm{PC} 88 \mathrm{~A}$, extraction isotherm was obtained at an aqueous-to-organic (A: O) phase ratio of $1: 1-3$ and $\mathrm{O}:$ A ratio of $1: 1-5$, which predicted possible separation of $\mathrm{Al}$ in 2 stages at A/O ratio of 2. Quantitative stripping was achieved by $\mathrm{H}_{2} \mathrm{SO}_{4}$.
\end{abstract}

\section{Introduction}

Nickel is primarily used as an alloying metal. The other uses of $\mathrm{Ni}$ are in electroplating batteries and as catalysts. Sulfidic, oxidic nickel ores and various nickel bearing secondary materials, such as super alloy scrap, spent batteries, and catalysts are potential sources for Ni production. Preparation of Ni-based catalysts generally involves either an alloy of $\mathrm{Ni}-\mathrm{Al}$, impregnation of $\mathrm{Ni}$ over the oxide supports of $\mathrm{Al}$, $\mathrm{Si}, \mathrm{Mg}$, in the matrix of $\mathrm{Al}-\mathrm{Mg}$ as hydrotalcites. Ni-based catalysts are widely used in petroleum, petrochemical, and pharmaceutical industry. After the usage of catalyst for a certain period of time, its activity reduces, at this stage, it is considered as spent. Spent catalysts are harmful to the environment due to the presence of soluble/leachable organic and inorganic compounds $[1,2]$.

A number of hydro- and pyrometallurgical processes have been proposed for metals recovery from spent catalysts, fly ash, and boiler ash. In general, untreated or pretreated spent catalyst materials are leached with mineral acids alone or their mixtures, sometimes in the presence of additives such as hydrogen peroxide, for the dissolution/leaching of valuable metals. Invascanu and Roman [3], Al-Mansi and Abdel Monem [4], and Abdel-Aal and Rashad [5] optimized the conditions for extraction of $\mathrm{Ni}$ using $\mathrm{H}_{2} \mathrm{SO}_{4}$ as leaching reagent. Other authors like Loboiko et al. [6], Vicol et al. [7], and Chaudhary et al. [8] studied leaching for recovery of $\mathrm{Ni}$ by using different reagents. Leach liquors obtained by acid treatment of these spent catalysts results in leach solutions containing major content of $\mathrm{Ni}$ and less quantities of $\mathrm{Al}$, $\mathrm{Mg}$, and Si. The metals are recovered as mixed solutions and then nickel separated is through conventional separation techniques such as precipitation, solvent extraction, and ion exchange, leaving other metals. In the present study, leach liquor obtained through dilute sulphuric acid leaching of spent Raneynickel catalyst containing about $85 \mathrm{~g} / \mathrm{L} \mathrm{Ni}$ and $3.25 \mathrm{~g} / \mathrm{L} \mathrm{Al}$ with a $\mathrm{pH}$ of 0.7 was used Lee et al. [9] for the purification of $\mathrm{NiSO}_{4}$.

The separation and recovery of $\mathrm{Al}$ by solvent extraction has been studied by several authors under different experimental conditions and in the presence of different associated metals. Acidic organophosphorus extractants are recommended by Meyer Fekete. [10] for the Al extraction and separation of $\mathrm{Fe}$ and $\mathrm{Al}$ from acidic solutions similar to the 
pickling bath solution. Mishra and Dhadke, [11], examined Cyanex 921 diluted in cyclohexane for the separation of $\mathrm{Be}(\mathrm{II})$ and $\mathrm{Al}(\mathrm{III})$. Beryllium extraction was effective in the $\mathrm{pH}$ range $8-10$ and $\mathrm{Al}$ extraction in the $\mathrm{pH}$ range 4.55.5. SX of $\mathrm{Al}(\mathrm{III})$ from aqueous succinate media using $\mathrm{n}$ octylaniline in toluene resulted in maximum $\mathrm{Al}$ extraction in the $\mathrm{pH}$ range 5.9-6.2, Shilimkar et al. [12]. SX of trivalent $\mathrm{Al}$ and $\mathrm{Ga}$ from alkali solution containing tartaric acid by trioctylmethylammonium chloride, Hiroshi and Yasushi [13], from weakly acidic medium with di-nbutyldithiophosphoric acid (DBTPA) and di-(2-ethylhexyl) dithiophosphoric acid (DETPA) in kerosene, in the presence and absence of alcohols and tri- $n$-butyl phosphate (TBP) Tóth et al. [14] from Co, $\mathrm{Ni}$, and Mg, Tsakiridis and AgatziniLeonardou [15] have been reported. Two-stage leaching of activated spent HDS catalyst followed solvent extraction of Al using Cyanex 272 as an extractant for the separation of $\mathrm{Al}$ from Ni and Co, Park et al. [16]. Solvent extraction and separation of $\mathrm{Al}$ has been reported by many researchers using various extractants Zaki et al. [17]; Nagib et al. [18].

The present research work is aimed at the solvent extraction of $\mathrm{Al}$ by organophosphorus-based extractants, in the presence of $\mathrm{Ni}$ from sulphate leach liquor of spent Raneynickel catalyst. Experimental analysis of the data was used to determine the main effects and interactions of the chosen factors and select the optimum conditions. The factors studied were effect of equilibrium $\mathrm{pH}$, screening of extractants, $\mathrm{A}: \mathrm{O}$ phase ratio, and counter-current extraction simulation for Al. Studies on stripping of metal loaded organic phase and regeneration and reuse of extractant were also reported.

\section{Experimental}

2.1. Apparatus and Reagents. A Perkin-Elmer Model A 300 atomic absorption spectrophotometer (AAS) and a digital Digisun $\mathrm{pH}$ meter (model DI 707) were used. TOPS 99, Talcher Organo Phosphorus Solvent an equivalent of di (2-ethylhexyl) phosphoric acid from Heavy Water Plant, Talcher, India, PC 88 A (2-ethylhexyl phosphonic acid mono 2-ethylhexyl ester, Daihachi, Japan) and Cyanex 272 Bis (2,4,4-trimethyl pentyl phosphinic acid), Cytec, Canada, were used as extractants. Distilled kerosene (b.p: $160-200^{\circ} \mathrm{C}$ ) mostly aliphatic $(96.2 \%)$, was used as diluent. All other chemicals used were analytical grade. Spent Raneynickel catalyst sulphate leached solution containing $0.12 \mathrm{M} \mathrm{Al}$ and 1.448 M Ni was used for present study, Lee et al. [9].

2.2. Solvent Extraction Procedure. Suitable volumes of aqueous and organic phases $(50 \mathrm{~mL}$ each) were taken in a $250 \mathrm{~mL}$ glass reactor, which had a provision to insert the electrode and measure the $\mathrm{pH}$ of the aqueous phase during extraction experiments. Both the phases were stirred for $5 \mathrm{~min}$ (initial experiments showed that equilibrium was reached within $1 \mathrm{~min}$ ), adjusted to the desired $\mathrm{pH}$ values with the addition of $50 \mathrm{wt} / \mathrm{vol} \% \mathrm{NaOH} / \mathrm{or}_{2} \mathrm{SO}_{4}$ solution. The phases were allowed to separate and the metal concentration in the aqueous phase was measured directly after suitable dilutions

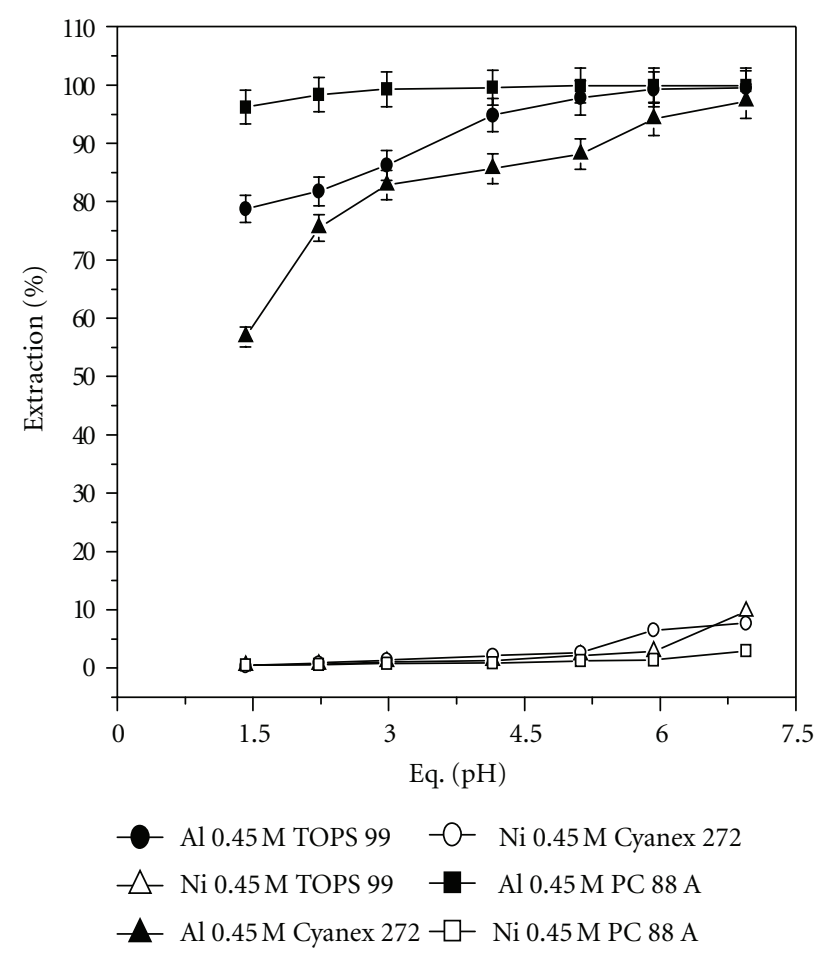

FIGURE 1: Equilibrium $\mathrm{pH}$ on percentage extraction of $\mathrm{Al}$ and $\mathrm{Ni}$; conditions: $\mathrm{Al}=3.25 \mathrm{~g} / \mathrm{L} ; \mathrm{Ni}=85 \mathrm{~g} / \mathrm{L}$; reagents $=0.45 \mathrm{M}$; TOPS 99; PC 88 A; Cyanex 272; equilibrium pH, 1-7.0.

by AAS. The loaded organic phases were stripped three times with $2 \mathrm{M} \mathrm{H}_{2} \mathrm{SO}_{4}$ wherever necessary, and the combined strip solutions were analysed for metal values after proper dilution by AAS. All the experiments were carried out at room temperature $\left(25 \pm 1^{\circ} \mathrm{C}\right)$. The distribution ratio, $D$, was calculated as the ratio concentration of metal present in the organic phase to that in the aqueous phase at equilibrium. From the $D$ values, the percentage extraction

$\left(\% E=D \times 100 /\left[D+\left(V_{\mathrm{aq}} / V_{\text {org }}\right)\right]\right)$ where $V_{\text {aq }}$ and $V_{\text {org }}$ are the volumes of aqueous and organic phases, respectively, and separation factor $\left(\beta=D_{\mathrm{Al}} / D_{\mathrm{Ni}}\right)$ was calculated.

\section{Results and Discussion}

3.1. Effect of Equilibrium $p H$ on Extraction of Metals. Figure 1 shows the effect of equilibrium $\mathrm{pH}$ versus percentage extraction of $\mathrm{Al}$ and $\mathrm{Ni}$ with $0.45 \mathrm{M}$ concentration of TOPS 99, Cyanex 272, and PC 88 A. In case of TOPS 99 as the extractant in the equilibrium $\mathrm{pH}$ range of 1.42 to 7 , it was observed that the percentage extraction of $\mathrm{Al}$ increased from 78.8 to $94.9 \%$ up to an equilibrium $\mathrm{pH}$ of 4.15 and thereafter reaches $99.5 \%$ at an equilibrium $\mathrm{pH}$ of 7 . In the equilibrium $\mathrm{pH}$ region of 4.15 to 7.0 , the coextraction of $\mathrm{Ni}$ was increased from 1.3 to $9.8 \%$. Using PC $88 \mathrm{~A}$ as the extractant in the equilibrium $\mathrm{pH}$ range 1.42 to 5.21 , it was observed that $\mathrm{Al}$ extraction was increased from 98.2 to $99.9 \%$ whereas the co-extraction of $\mathrm{Ni}$ increased from 0.5 to $1.3 \%$. Using Cyanex 272 as the extractant in the equilibrium $\mathrm{pH}$ range 1 to 7 , it was observed that $\mathrm{Al}$ extraction increased from 


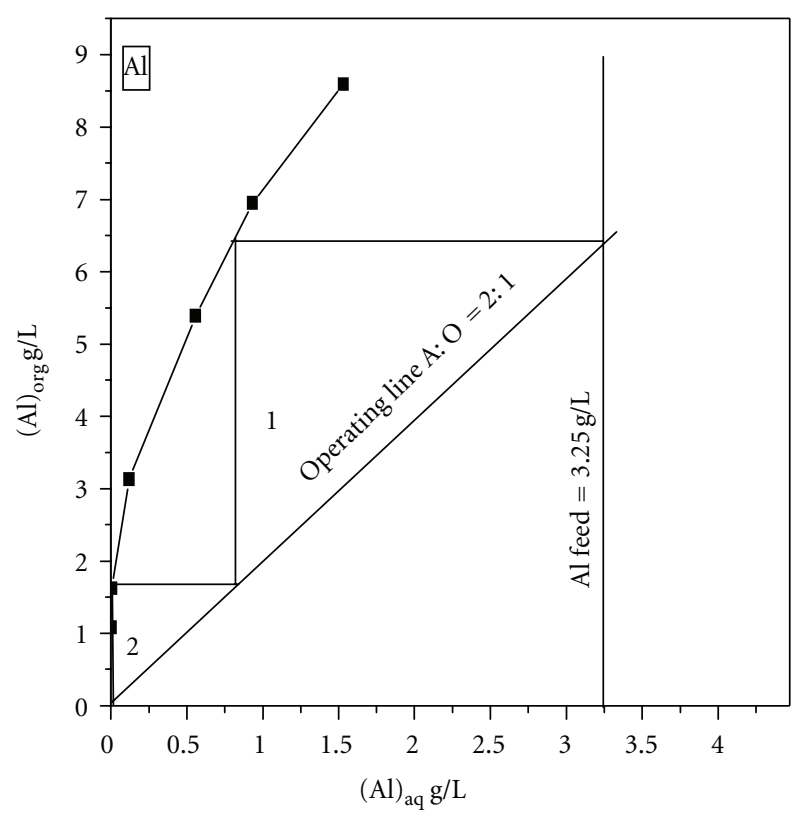

Figure 2: McCabe-Thiele plot for $\mathrm{Al}$ extraction. Conditions: $\mathrm{Al}=$ $3.25 \mathrm{~g} / \mathrm{L} ; \mathrm{Ni}=85 \mathrm{~g} / \mathrm{L}$; equilibrium $\mathrm{pH}, 2.23 ; \mathrm{A} / \mathrm{O}, 1 / 1-3$ and $\mathrm{O} / \mathrm{A}$, $1 / 1-5$.

56.8 to $88.5 \%$ in the equilibrium pH range from 1 to 4 and finally reached to $97.3 \%$ at an equilibrium $\mathrm{pH}$ of 7.0 whereas the coextraction of $\mathrm{Ni}$ increased from 0.4 to $7.7 \%$ in the equilibrium $\mathrm{pH}$ region 1 to 7 . Among the three reagents, we have selected $0.45 \mathrm{M}$ PC $88 \mathrm{~A}$ for further studies on $\mathrm{Al}$ separation from $\mathrm{Ni}$ at an equilibrium $\mathrm{pH}$ of $2.23(98.6 \% \mathrm{Al}$ and $0.65 \% \mathrm{Ni}$ coextraction) as it showed better extraction efficiency of $\mathrm{Al}$ than the others.

3.2. Effect of Phase Ratio on Al Extraction. To determine the number of stages required at a chosen volume phase ratio for quantitative extraction of $\mathrm{Al}$, the extraction isotherm was obtained at different $\mathrm{A}: \mathrm{O}$ phase ratios from $1: 1-3$ and $\mathrm{O}: \mathrm{A}$ phase ratios from $1: 1-5$ by contacting the aqueous feed and organic phase $(0.45 \mathrm{M}$ PC $88 \mathrm{~A})$ at an equilibrium $\mathrm{pH} 2.23$ (Figure 2). From the McCabe-Thiele plot, it can be concluded that $\mathrm{Al}$ extraction increased from 98.6 to $99.6 \%$ with an increase of $\mathrm{A}: \mathrm{O}$ ratio from $1: 1$ to 3 and decreased from 98.6 to $52.8 \%$ at an increase of $\mathrm{O}:$ A ratio from $1: 1$ to 5. The results also indicate that $\mathrm{Al}$ extraction efficiency of $>99.0 \%$ can be achieved, if the extraction is performed in two counter-current stages at $\mathrm{A}: \mathrm{O}$ phase ratio of $2: 1$, where $\mathrm{Al}$ extraction efficiency in single stage is about $98.2 \%$.

\subsection{Counter-Current Extraction Studies for Al Extraction} (CCES). Based on the data obtained from the McCabeThiele plot on $\mathrm{Al}$ extraction with $0.45 \mathrm{M}$ PC $88 \mathrm{~A}$ in kerosene, a two-stage counter current extraction simulation test at A : O 2: 1 ratio (single stage: $98.2 \% \mathrm{Al}$ extraction) was carried out at equilibrium $\mathrm{pH} 2.23$ in order to confirm the $\mathrm{Al}$ extraction isotherm prediction data. The raffinate and loaded organic outlet streams were collected after the second cycle

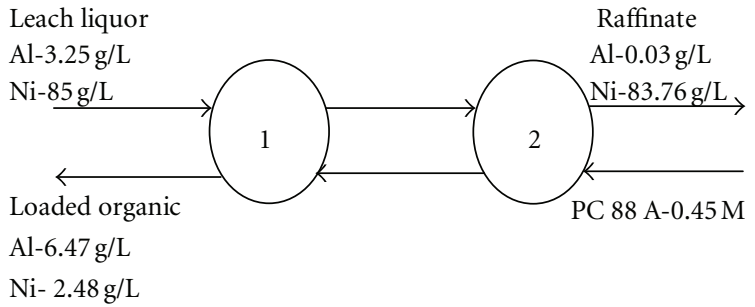

Figure 3: Two stage CCES for Al. Conditions: $\mathrm{Al}=3.25 \mathrm{~g} / \mathrm{L} ; \mathrm{Ni}=$ 85 g/L; PC 88 A-0.45 M; equilibrium pH, 2.23.

TABLE 1: Effect of stripping agents on stripping efficiency of $\mathrm{Al}$ from loaded organic (L.O; $6.47 \mathrm{~g} / \mathrm{L}$ ).

\begin{tabular}{lcc}
\hline Stripping agent & Concentration (M) & $\mathrm{Al}$ stripping (\%) \\
\hline \multirow{3}{*}{$\mathrm{HCl}$} & 0.1 & 34.6 \\
& 0.5 & 52.3 \\
& 1.0 & 87.4 \\
\hline $\mathrm{HNO}_{3}$ & 0.1 & 39.0 \\
& 0.5 & 68.9 \\
& 1.0 & 83.5 \\
$\mathrm{H}_{2} \mathrm{SO}_{4}$ & 0.1 & 53.9 \\
& 0.5 & 74.3 \\
& 1.0 & 99.6 \\
\hline
\end{tabular}

onwards and analyzed for metal values. The loaded organic (L.O) contains $6.47 \mathrm{~g} / \mathrm{L}$ Al. The raffinate contained $0.03 \mathrm{mg} / \mathrm{L}$ $\mathrm{Al}$ corresponding to $99.1 \%$ extraction efficiency. Loss of $\mathrm{Ni}$ was $1.46 \%$ only (Figure 3 ).

3.4. Effect of Stripping Agents. Stripping is the reverse of the extraction, so it should be promoted by these factors that effect extraction negatively, such as acidic, basic, and salt media. Al stripping from loaded organic (L.O) $0.45 \mathrm{M}$ PC 88 A containing $6.47 \mathrm{~g} / \mathrm{L} \mathrm{Al}$, was investigated using various stripping agents such as $\mathrm{HCl}, \mathrm{HNO}_{3}$, and $\mathrm{H}_{2} \mathrm{SO}_{4}$ in the range $0.1-1.0 \mathrm{M}$ at unit phase ratio. The results are presented in Table 1. It was found that stripping efficiency increased with increasing acid concentration and reaches its maximum at $1.0 \mathrm{M}$. Comparison of stripping data at $1 \mathrm{M}$ acids, it is clear that $\mathrm{H}_{2} \mathrm{SO}_{4}$ is the most effective acid for $\mathrm{Al}$ stripping followed by $\mathrm{HCl}$ and $\mathrm{HNO}_{3}$. Further, the effect of different $\mathrm{O}$ : A phase ratios on $\mathrm{Al}$ stripping efficiency and number of theoretical stages required for quantitative stripping are presented in Table 2. Al stripping efficiency of $99.6 \%$ was achieved in a single stage using $1.0 \mathrm{M} \mathrm{H}_{2} \mathrm{SO}_{4}$. By increasing the $\mathrm{O} / \mathrm{A}$ ratio to $>1$, the stripping efficiency decreased and the numbers of stages are required for quantitative stripping increased as expected.

3.5. Regeneration and Reuse of the Reagents. The Al containing organic phases were stripped with acidified distilled water at an equal phase ratio. The stripped organic phases were again washed with distilled water for 2-3 times. The regenerated stripped solvents were reused after washing with deionized water for the determination of extraction 


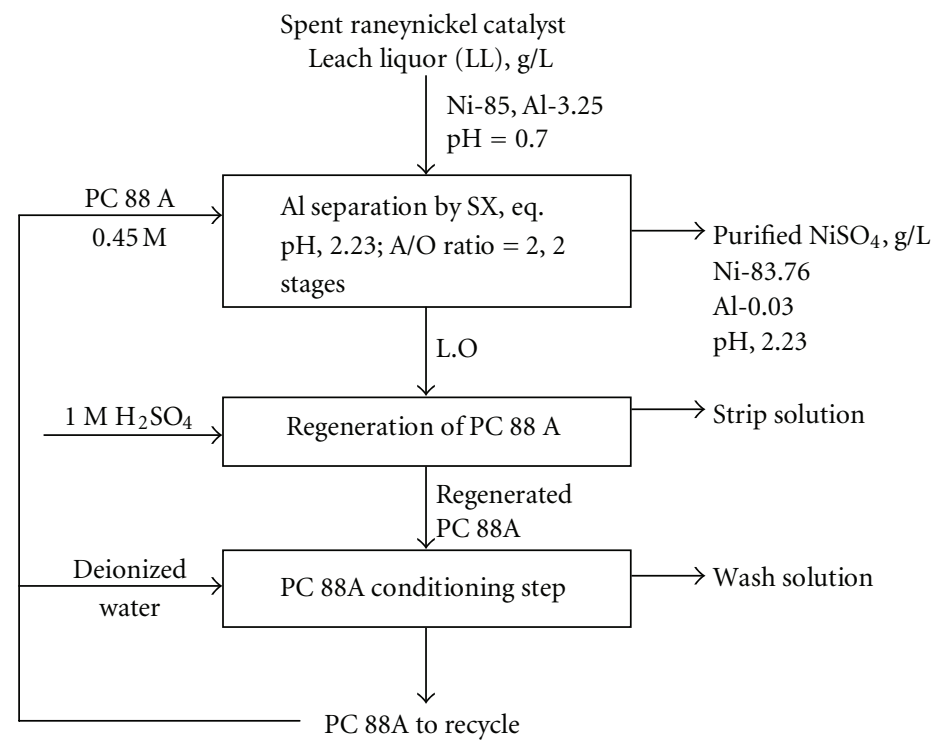

Figure 4: Regeneration and reuse of PC $88 \mathrm{~A}$.

TABLE 2: Effect of phase ratio on $\mathrm{Al}$ stripping from loaded organic (L.O). $\mathrm{Al}$ in L.O $=6.47 \mathrm{~g} / \mathrm{L} \mathrm{H}_{2} \mathrm{SO}_{4} ; 1 \mathrm{M}$, time: 15 min.

\begin{tabular}{lccc}
\hline Extractant & Phase ratio $(\mathrm{O}: \mathrm{A})$ & Al stripping efficiency $(\%)$ & Theoretical number of stages to get $>99 \%$ efficiency \\
\hline & $1.0: 1$ & 99.6 & 1 \\
PC 88 A & $1.5: 1$ & 95.9 & 2 \\
& $2.0: 1$ & 80.0 & 4 \\
\\
$2.5: 1$ & 71.0 & 61.3 & 5 \\
\hline
\end{tabular}

efficiency of $\mathrm{Al}$ for 5 cycles (Figure 4), and found that extraction and stripping efficiency were the same (standard deviation of $\pm 2 \%$ ).

\section{Conclusion}

Solvent extraction studies of $\mathrm{Al}$ from sulphate solutions by organophosphorus-based extractants establish the dependence of $\mathrm{Al}$ extraction on equilibrium $\mathrm{pH}$ of the aqueous phase. The results demonstrate that among the phosphoric, phosphonic, and phosphinic reagents, phosphonic acid, that is, $\mathrm{PC} 88 \mathrm{~A}$ is the better reagent for the separation and recovery of $\mathrm{Al}$ from $\mathrm{Ni}$ from sulphate leach solution of Raneynickel catalyst. Al extraction efficiency of $>99 \%$ is achieved in two stages at an $\mathrm{A}: \mathrm{O}$ phase ratio of $2: 1$ and equilibrium $\mathrm{pH}$ of 2.23 with $\mathrm{PC} 88 \mathrm{~A}$. Quantitative $\mathrm{Al}$ stripping can be achieved in single stage from loaded organic phase using $1.0 \mathrm{M} \mathrm{H}_{2} \mathrm{SO}_{4}$ by operating stripping at $\mathrm{O} / \mathrm{A}$ ratio of 1-1.5. Finally, the present methodology can yield high pure Ni LL suitable for production of hydrated $\mathrm{NiSO}_{4}$ by evaporation and crystallization.

\section{Acknowledgments}

The authors would like to thank President Dr. Hyo Sook Lee and Dr. Byung Soo Kim Leader of Urban Mining Research
Team for their constant encouragement and permission to publish this paper. S. V. Rao thanks KIGAM for PDF position.

\section{References}

[1] D. Rapaport, "Are spent hydrocracking catalysts listed hazardous wastes?" Hydrocarbon Processing, vol. 79, no. 7, pp. 4953,2000

[2] United Stated Environmental Protection Agency (USEPA), "Hazardous waste Management system," Federal Register, vol. 68, pp. 59935-59940, 2003.

[3] St. Invascanu and O. Roman, "Nickel recovery from spent catalysts: solvation process," Buletinul Institutului Politehnic Lasi, vol. 2, p. 47, 1975.

[4] N. M. Al-Mansi and N. M. Abdel Monem, "Recovery of nickel oxide from spent catalyst," Waste Management, vol. 22, no. 1, pp. 85-90, 2002.

[5] E. A. Abdel-Aal and M. M. Rashad, "Kinetic study on the leaching of spent nickel oxide catalyst with sulfuric acid," Hydrometallurgy, vol. 74, no. 3-4, pp. 189-194, 2004.

[6] A. Y. Loboiko, V. I. Atroshchenko, G. I. Grin, and V. V. Kutovoi, "Recovering nickel from spent catalyst," Otkrytiya, Izobret, Prom Obraztsy. Tovarnye Znaki, vol. 14, p. 33, 1983.

[7] M. Vicol, A. Heves, and M. Potoroaca, "Recovery of nickel from spent catalysts," Combinatul de Ingrasaminte Chimice. Piatra-Neamt, vol. 112, p. 832, 1986.

[8] A. J. Chaudhary, J. D. Donaldson, S. C. Boddington, and S. M. Grimes, "Heavy metals in the environment. Part II: 
a hydrochloric acid leaching process for the recovery of nickel value from a spent catalyst," Hydrometallurgy, vol. 34 , no. 2 , pp. 137-150, 1993.

[9] J. Y. Lee, S. V. Rao, B. N. Kumar, D. J. Kang, and B. R. Reddy, "Nickel recovery from spent Raneynickel catalyst through dilute sulfuric acid leaching and soda ash precipitation," Journal of Hazardous Materials, vol. 176, no. 1-3, pp. 11221125,2010

[10] G. S. O. Meyer and G. R. Fekete, "Selective extraction of iron and aluminum from acidic solutions," U. S. Patent, no. 4,233,273, 1980.

[11] B. Y. Mishra and P. M. Dhadke, "Solvent extraction separation of beryllium(II) from aluminum(III) by Cyanex 921 (TOPO)," Separation Science and Technology, vol. 33, no. 11, pp. 1681$1692,1998$.

[12] T. N. Shilimkar, S. S. Kolekar, and M. A. Anuse, "Rapid extraction separation of aluminium(III) from associated elements with n-octylaniline from succinate media," Separation and Purification Technology, vol. 42, no. 1, pp. 55-63, 2005.

[13] W. Hiroshi and K. Yasushi, "Extraction of trivalent aluminium and gallium from sodium hydroxide solutions containing tartaric acid by trioctylmethylammonium chloride," Solvent Extraction Research and Development, vol. 2000, no. 7, pp. 118-126, 2000.

[14] I. Tóth, E. Brücher, and Z. Szabó, "Extraction of gallium(III) and aluminium(III) with O,O-dialkyldithiophosphoric acids," Talanta, vol. 37, no. 12, pp. 1175-1178, 1990.

[15] P. E. Tsakiridis and S. Agatzini-Leonardou, "Solvent extraction of aluminium in the presence of cobalt, nickel and magnesium from sulphate solutions by Cyanex 272," Hydrometallurgy, vol. 80, no. 1-2, pp. 90-97, 2005.

[16] K. H. Park, D. Mohapatra, and C. W. Nam, "Two stage leaching of activated spent HDS catalyst and solvent extraction of aluminium using organo-phosphinic extractant, Cyanex 272," Journal of Hazardous Materials, vol. 148, no. 1-2, pp. 287-295, 2007.

[17] E. E. Zaki, Z. H. Ismail, J. A. Daoud, and H. F. Aly, "Extraction equilibrium of beryllium and aluminum and recovery of beryllium from Egyptian beryl solution using CYANEX 921," Hydrometallurgy, vol. 80, no. 4, pp. 221-231, 2005.

[18] S. Nagib, K. Inoue, T. Yamaguchi, and T. Tamaru, "Recovery of $\mathrm{Ni}$ from a large excess of $\mathrm{Al}$ generated from spent hydrodesulfurization catalyst using picolylamine type chelating resin and complexane types of chemically modified chitosan," Hydrometallurgy, vol. 51, no. 1, pp. 73-85, 1999. 


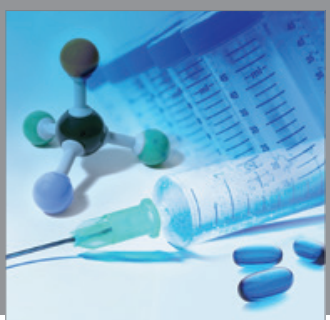

International Journal of

Medicinal Chemistry

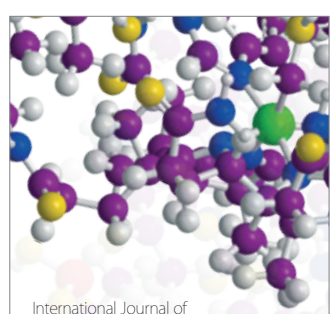

Carbohydrate Chemistry

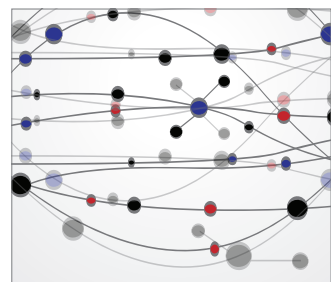

The Scientific World Journal
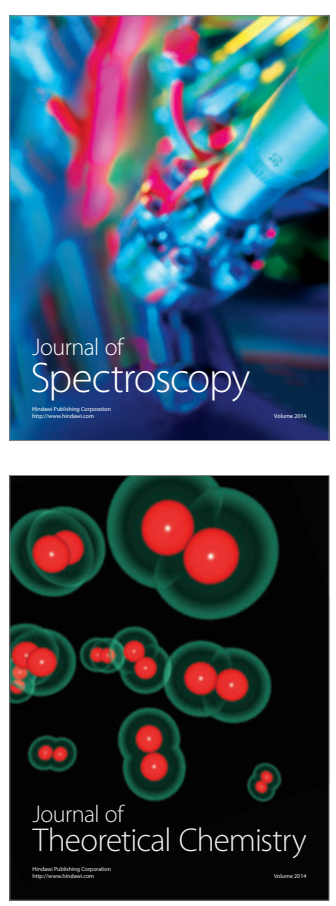
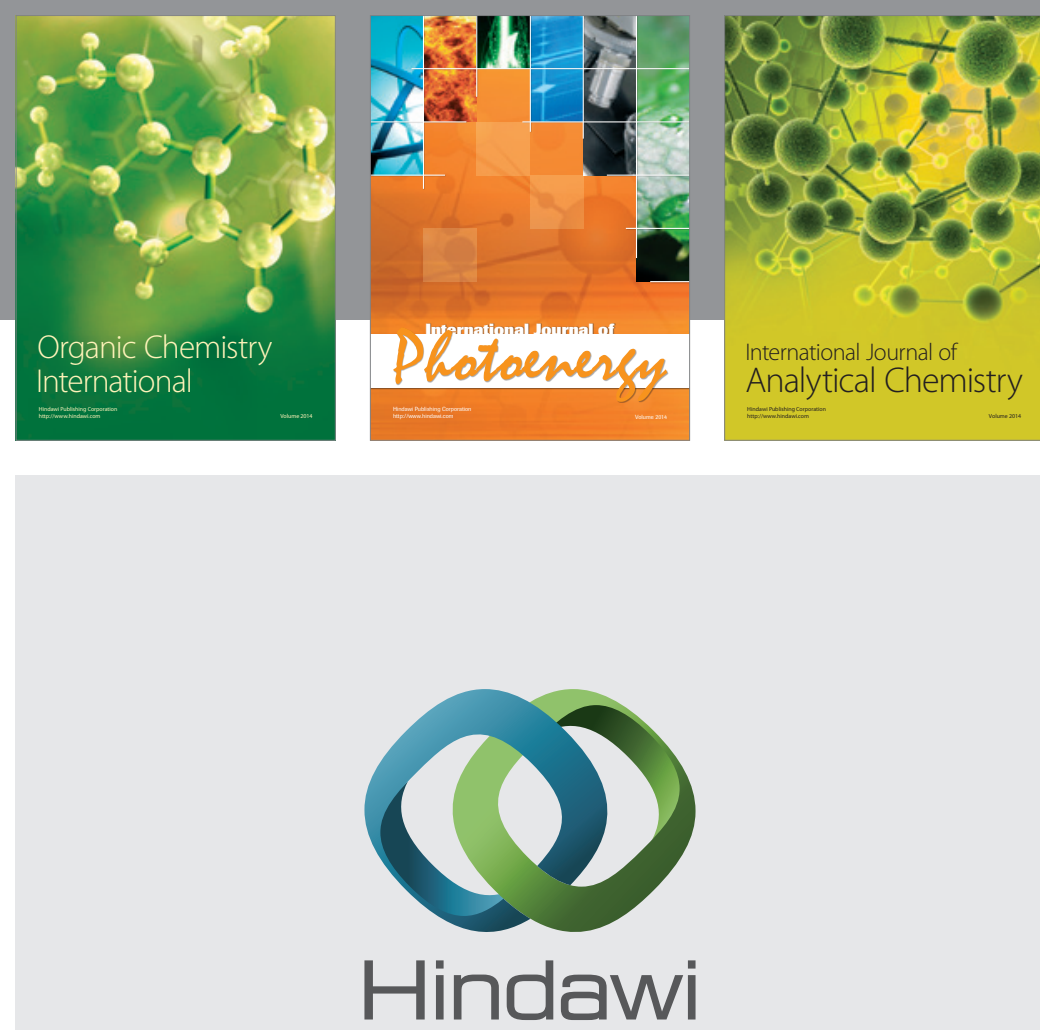

Submit your manuscripts at

http://www.hindawi.com
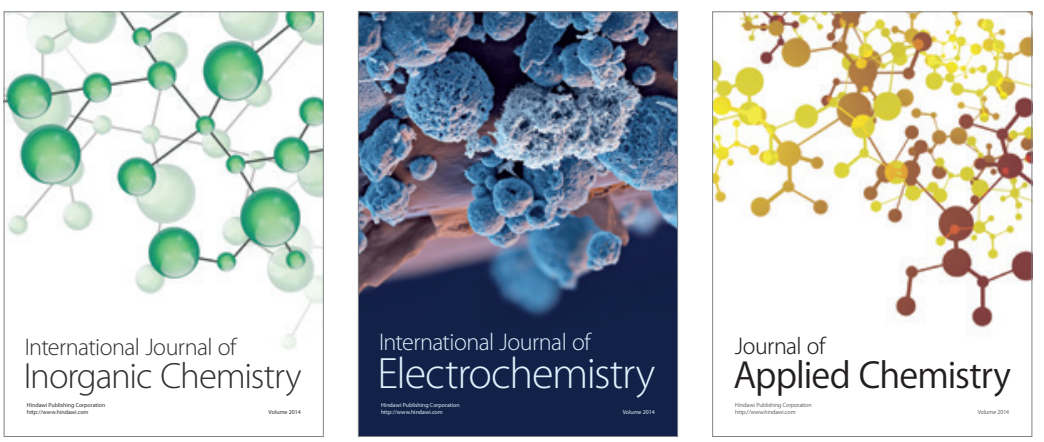

Journal of

Applied Chemistry
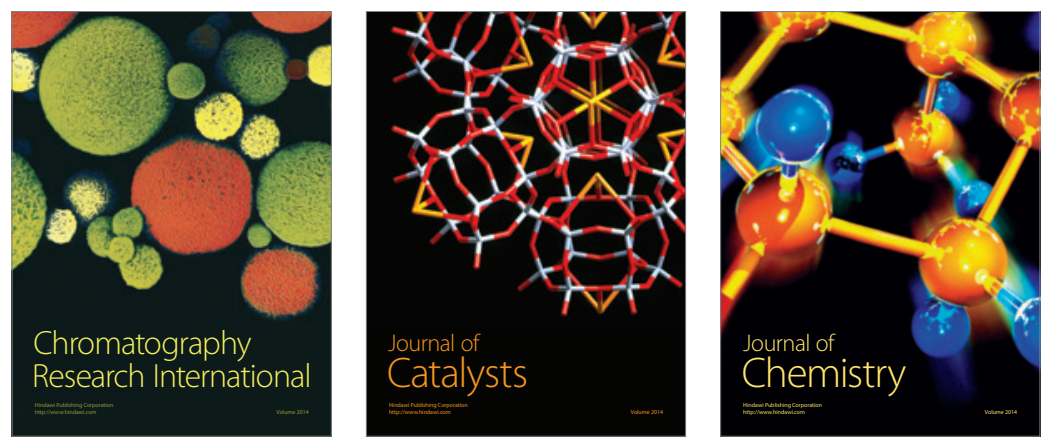
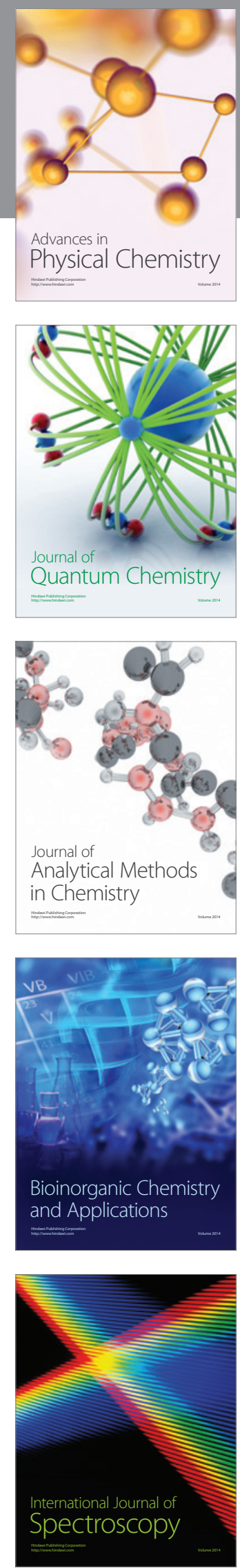